\title{
MÚSICA, COMPORTAMENTO SOCIAL E RELAÇÕES INTERPESSOAIS
}

\author{
Beatriz llari
}

\begin{abstract}
RESUMO. O objetivo desta investigação foi verificar o papel da música na atração interpessoal, escolha de parceiros e relacionamentos afetivos. Cinqüienta adultos não-músicos escolheram possíveis parceiros através de classificados pessoais, descreveram as características de ouvintes de 7 gêneros musicais diferentes e responderam a questões referentes ao uso da música em seus relacionamentos afetivos. Embora a música não tenha tido um efeito direto sobre a atração interpessoal e a escolha de parceiros, ela aparentou ter alguns efeitos indiretos nas relações interpessoais. Alguns estereótipos de personalidade associados aos gêneros musicais foram encontrados, sugerindo que o gosto musical pode influenciar na escolha de parceiros. Além disso, emergiram quatro categorias relacionadas ao uso da música no contexto das relações interpessoais: objetivos de excitação, fundo acústico, facilitadora de atividades que promovem a aproximação e artefato mnemônico. Os dados desta investigação reforçam a idéia de que a música exerce um papel importante nas relações interpessoais.
\end{abstract}

Palavras-chave: cognição social, música, estereótipos.

\section{MUSIC, SOCIAL BEHAVIOR AND INTERPERSONAL RELATIONSHIPS}

\begin{abstract}
The purpose of this study was to investigate the effects of music on interpersonal relationships by means of attraction, choice of partners, and romantic relationships. Fifty adult non-musicians chose potential partners in newspaper ads, described the characteristics of listeners of 7 different musical styles, and answered open-ended questions related to the uses of music in interpersonal relationships of a romantic nature. Although music did not seem to impact interpersonal attraction and choice of partners directly, it was found to impact social bonding in indirect ways. Personality types associated with musical styles emerged, suggesting that musical taste influences interpersonal relationships. Additionally, four categories related to the uses of music in the context of interpersonal relationships emerged including arousal goals, background, facilitator of activities that foster proximity, and mnemonic artifact. Data from this study lends support to the notion that music plays an important role in social bonding.
\end{abstract}

Key words: Social cognition, music, stereotypes.

No que se refere à causa e efeito biológicos, a música é inútil. Ela não aponta para um caminho que garanta objetivos como uma vida longa, a existência de netos, ou uma percepção e previsão exatas do mundo. Se comparada à linguagem, visão, pensamento social, e conhecimento físico, a música poderia desaparecer de nossa espécie deixando o resto de nosso estilo de vida praticamente inalterado $^{1}$ ( Pinker, p. 528).

Desde que o lingüista americano Steven Pinker fez a afirmativa acima, vários estudiosos têm escrito em favor da causa musical, na tentativa de fornecer uma explicação sobre o papel da música na evolução (veja Cross, 1999; Huron, 1999).
Apesar de todos os esforços de pesquisadores em campos como a neurociência e a genética, até o momento não existem evidências que possam comprovar a existência de um gene musical propriamente dito. Entretanto, a música continua a ter um caráter universal e a exercer um papel importante nas sociedades e culturas. Segundo Gregory (1997), a música é um fenômeno social que vem mantendo funções tradicionais e sentidos próprios em diferentes sociedades, no decorrer da história. Para os Iorubás da África, por exemplo, o uso da música implica na idéia de parentesco, religião, política e economia (Campbell, 1996). Já para os capoeiras, a música está associada ao movimento corporal, ao ritual e à libertação (Ilari, 2001). Como sugere Gregory (1997), tanto as

* Doutora. Professora Departamento de Artes, Universidade Federal do Paraná-UFPR.
1 Tradução da autora. 
funções quanto os significados do fazer musical dependem de aspectos específicos de cada sociedade e cultura.

No Mundo Ocidental a música vem exercendo funções específicas em atividades humanas como ninar crianças, dançar, contar estórias, comemorar eventos especiais, vender produtos, entreter, curar e rezar, anunciar eventos, entre outras (Gregory, 1997; Ilari \& Majlis, 2002). Estas e as muitas outras funções da música na vida cotidiana estão claramente relacionadas às relações interpessoais. Partindo dessa premissa, Huron (1999) sugere que, no tocante à evolução da espécie, a música exerce um papel importante, por criar cenários para os relacionamentos humanos, inclusive aqueles de natureza amorosa. Segundo a teoria de Huron (1999), a música exerce alguns efeitos sobre a atração e sobre o desenvolvimento subseqüente de relações interpessoais.

$\mathrm{Na}$ literatura científica, há um certo consenso de que a atração interpessoal constitui um dos componentes do desenvolvimento das relações entre os indivíduos, incluindo aquelas de natureza fraternal e amorosa (Reeder, 2000). A atração interpessoal pode ser definida como uma experiência que leva os indivíduos a relatarem uma conexão especial com os outros (Reeder), sendo de interesse para diversas áreas do conhecimento. Tomando-se uma perspectiva evolucionária, a atração interpessoal é obviamente vista como um elemento crucial no desenvolvimento de vínculos que possam resultar na geração de descendentes, e assim sendo, na continuação da espécie. Sob a ótica da psicologia cognitiva, a atração está relacionada aos esquemas cognitivos que são construídos a partir dos ideais de parceiros e relacionamentos amorosos (Fletcher, Giles, Simpson \& Thomas, 1999). Baseados em experiências pessoais, estes ideais são gradativamente construídos no decorrer da vida. Localizados no nicho cognitivo direito, os ideais exercem uma influência considerável sobre o pensamento e o comportamento nas relações interpessoais (Fletcher, Giles, Simpson \& Thomas). Em outras palavras, a atração interpessoal não ocorre de maneira pueril, mas está diretamente ligada aos esquemas cognitivos que, consciente ou inconscientemente, são mediados por experiências anteriores com colegas e responsáveis (Priel \& Besser, 2000).

Os estudiosos das relações interpessoais já identificaram uma série de fatores que estão associados à atração interpessoal. A atração física constitui um destes fatores (Myers, 1993). Alguns estudos sugerem que o sexo masculino valoriza mais a atração física do que o sexo feminino (Feingold, 1990), embora haja um certo consenso de que os indivíduos com boa aparência são geralmente os mais atraentes (Myers, 1993), mesmo em contextos nos quais a aparência não constitui o elemento preponderante (Wapnick, Mazza \& Darrow, 1998). Proximidade, interação e exposição continuada aos outros indivíduos são alguns outros fatores que contribuem para o aumento da atração interpessoal (Myers, 1993). Além disso, uma semelhança real ou percebida entre os indivíduos também aparenta contribuir para o desenvolvimento da atração entre os indivíduos (Myers, 1993; Reeder, 2000). Atitudes, crenças e valores comuns são vistos como forças poderosas da atração interpessoal, já que a atração em si é um processo dual que envolve as atitudes, os valores e as crenças pessoais não apenas do invidíduo que se sente atraído, mas também daquele que é o objeto da atração (Myers, 1993). Tais atitudes, crenças e valores são determinados por vários fatores, inclusive o contexto social e a cultura, que são transmitidos através das diferentes relações de uma rede social e exercem um papel vital no estabelecimento da atração e subseqüente desenvolvimento de relações interpessoais (Felmlee $\&$ Sprecher, 2000). Isso sugere que a atração interpessoal depende do contexto social, que forma atitudes, crenças pessoais e valores. Coincidentemente, o mesmo pode ser dito a respeito da formação do gosto musical.

Embora sejam completamente diferentes, a atração e a música têm algo em comum: ambas estão ligadas à indução e/ou surgimento de sentimentos. A conexão entre atração e afeto é bastante óbvia, porque quando se diz que alguém tem atração, geralmente isso quer dizer que há sentimentos específicos por alguém ou algo (Myers, 1993). Já a conexão música-afeto não é tão evidente, o que tem motivado diversas investigações (Juslin \& Sloboda, 2001; Krumhansl, 1997; Sloboda, 1991). No entanto, há certo consenso de que os sentimentos induzidos pela música têm implicações significativas para o comportamento social (Crozier, 1997), em parte porque gêneros musicais diferentes eliciam graus diferentes de excitação. North e Hargreaves (1997) especulam que são os objetivos de excitação contrastantes que possivelmente explicam a seleção de gêneros musicais diferentes, de acordo com os diversos contextos sociais. Enquanto uma peça de música rápida e em volume alto pode ser usada para elevar os níveis de excitação durante uma festa ou 
em uma casa noturna, uma canção de ninar calma e serena pode servir para diminuir o nível de excitação da criança cansada (Ilari, 2002; North \& Hargreaves, 1997; Trehub \& Schellenberg, 1995). Em outras palavras, as formas de utlização e apreciação da música variam de acordo com uma combinação de crenças pessoais e objetivos de excitação, entrelaçados àqueles do grupo social ao qual pertencemos. Além disso, o senso de "música apropriada" depende de fatores culturais e situacionais, uma vez que as respostas, as percepções e os usos da música são comportamentos aprendidos e previamente determinados por membros de um grupo social (Abeles, Hoffer \& Klotman, 1995). Como ficou dito, o grupo social exerce um papel preponderante no desenvolvimento de nossas preferências e subseqüente gosto musical.

Destarte, se a música e a atração têm em comum $o$ fato de ambas serem fortemente influenciadas pela cultura vigente e de eliciarem afeto, de que maneiras elas estão relacionadas? Qual papel a música exerce na atração interpessoal? Apenas recentemente é que a psicologia da música focou estas questões. Zillman e Bhatia (1989) investigaram os efeitos de associar a atração heterossexual aos estilos musicais, e concluíram que o gosto musical influencia a atração interpessoal, bem como a percepção e a avaliação da personalidade alheia. Alguns estereótipos associados a certos gêneros musicais foram encontrados, o que levou os autores a concluir que o gostar e a atração interpessoal estão relacionados às respostas individuais aos estereótipos. Segundo os autores, os estereótipos associados à música, que nada mais são do que esquemas cognitivos que passam pelo viés de categorias impostas social e culturalmente, aparentam ser determinantes nas atitudes interpessoais. A mera exposição ao símbolo ou ícone que representa uma destas categorias ou alguns aspectos do estereótipo de um determinado grupo pode ser suficiente para dar origem a associações estereotípicas, muitas vezes, de forma inconsciente (Johnson, Trawalter \& Dovidio, 2000). Não surpreendentemente, estes estereótipos influenciam a percepção e, conseqüentemente, a atração interpessoal.

O presente estudo teve três objetivos principais. Em primeiro lugar, o estudo buscou determinar o papel da música nas relações interpessoais, na atração e escolha de parceiros. Em segundo lugar, o estudo procurou verificar se os estereótipos associados aos gêneros musicais, encontrados em amostras norte-americanas e européias, poderiam ser encontrados numa amostra brasileira. Em terceiro e último lugar, o estudo investigou se existem ou não funções específicas da música nas relaçoes interpessoais, tomando por base os relatos dos participantes.

\section{MÉTODO}

\section{Amostra}

A amostra do presente estudo foi definida com base nos critérios adotados em estudos anteriores sobre o mesmo assunto (veja Johnson, Trawalter, \& Dovidio, 2000; Zillman \& Bhatia, 1989). Por esta razão, os participantes foram 60 jovens e adultos, de idade variável entre 12 e 43 anos, recrutados em um restaurante universitário da cidade de Campinas, SP. A participação no estudo foi voluntária e todos os participantes assinaram formulários de consentimento, antes de responderem ao instrumento de coleta de dados. Por razões óbvias, músicos profissionais ou amadores $(n=4)$, estudantes de música $(n=1)$ e participantes com mais de três anos de treino musical formal $(n=6)$ foram excluídos da amostra final.

Cinqüenta jovens e adultos (25 homens, 25 mulheres) com uma média de 27 anos de idade compuseram a amostra final. O grau de escolaridade dos participantes incluiu primeiro grau completo $(n=9)$, segundo grau completo $(n=11)$, universitário completo ou em andamento $(n=18)$, e pós-graduação $(n=12)$. Um pouco menos da metade da amostra teve algum tipo de treino musical $(n=23)$, por períodos de três meses a três anos (média $=1$ ano e 6 meses), embora nenhum participante estivesse tendo aulas de música na ocasião em que se deu a coleta de dados. Os instrumentos tocados pelos participantes incluíam: violão clássico $(n=11)$, piano $(n=8)$, flauta transversal $(n=3)$, bateria $(n=2)$, teclado $(n=1)$, violino, harpa, guitarra, orgão e cavaquinho (todos $n=1$ ).

\section{Procedimento}

Um instrumento de coleta de dados em três partes foi especialmente elaborado para este estudo. $\mathrm{Na}$ primeira parte, o participante foi exposto a cinco pares de classificados pessoais e deveria escolher, em cada par, o parceiro que lhe parecesse mais atraente. Os anúncios foram elaborados através de pesquisa em diversos jornais e sítios internet de paquera e namoro. Cada par consistiu 
em descrições semelhantes de possíveis parceiros, sendo que a variável música foi colocada em apenas um deles. A variável música se referiu à execução instrumental ou vocal, conforme ilustra a figura 1 abaixo.
A1 aparência, em forma, adora livros e culinária.

\section{B1}

\begin{tabular}{|lr}
\hline Divertido(a), & bem \\
humorado (a), & sincero(a), \\
inteligente, adora esportes e & \\
cantar num coral & amador.
\end{tabular}

\section{C1}

Estudante de $\mathrm{PhD}$, signo de virgem, ama comida italiana e TV. Nas horas livres, toca piano e pratica mergulho.

D1

Olá. Você gostaria da companhia de um flautista para um cineminha? Que tal um jantar romântico? Escreva para XX

E1

Hobbies: Aquários, línguas estrangeiras e partidas de tênis aos finais de semana.
Solteiro (a), residente no Rio de Janeiro, boa
A2

Carioca disponível com corpo atlético e cheio de beleza. Hobbies: tocar violão, fazer uma boa
comida e ler muito.

B2

Esportista, ótimo senso de humor, verdadeiro (a), altamente inteligente, divertido (a). Quero foto na $1^{\mathrm{a}}$

C2

Mergulhador, estudante de doutorado, virginiano(a). Adora macarrão, lasanha e assistir TV nas horas vagas.

\section{D2}

Jantar a dois? Acho uma ótima idéia. Ou será que você prefere um bom filme? Me avise, escrevendo para XX

\section{E2}

Estudante de idiomas, cultiva peixes ornamentais, joga tênis e toca pandeiro num grupo musical.
Figura 1. Anúncios de jornal

A segunda parte do instrumento de coleta de dados continha a seguinte proposição incompleta:

"As pessoas que ouvem geralmente (adjetivo)." (estilo musical) são

O participante deveria ler a proposição e escrever um mínimo de dois adjetivos para os sete gêneros musicais propostos: MPB, jazz, música clássica, samba/pagode, rock/pop e sertanejo. Estes gêneros foram escolhidos por integrarem a lista dos sete gêneros musicais mais populares de uma revista de música publicada no Brasil, com uma tiragem grande e ampla distribuição no território nacional. Exemplos de intérpretes, compositores e conjuntos musicais para cada gênero também foram fornecidos aos participantes, a fim de evitar confusões na definição de cada um.

A última parte do instrumento consistiu em questões abertas sobre sexo, idade, experiência educacional, experiência musical prévia e tempo médio de escuta musical, além de conter questões abertas relativas à importância da música nas relações interpessoais, nos namoros e em outros eventos da vida. Cada participante foi conduzido individualmente a uma sala silenciosa da universidade, onde recebeu o instrumento de coleta de dados impresso em papel A4 e foi instruído de que teria o prazo de 60 minutos para trabalhar. Os participantes levaram uma média de 35 minutos para responder aos quesitos do instrumento.

\section{RESULTADOS E DISCUSSÃO}

A primeira parte do estudo investigou os efeitos da música na atração interpessoal e escolha de parceiros. Para determinar se, de maneira geral, a escolha dos anúncios foi afetada pelo gênero do participante, a análise dos dados foi feita da seguinte maneira: - Os participantes que escolheram três ou mais anúncios que continham a variável musical foram colocados no grupo 1 , e os participantes que escolheram menos de três anúncios contendo a variável musical foram colocados no grupo 2. Um teste de chi-quadrado $2 \mathrm{X} 2$ modificado pelo fator Yates de correção foi aplicado aos dados e resultou na ausência de diferença entre os grupos $\left(x^{2}=1,86\right)$. A hipótese nula foi aceita, já que este valor ficou aquém do valor mínimo $\mathrm{x}^{2} \cdot 05(1)=3.84$ ( $\mathrm{p}>$.05). Concluiu-se que a música é possivelmente mais uma variável dentre as muitas que são consideradas na escolha de parceiros através de classificados. Em outras palavras, a música não pareceu ter efeitos positivos ou negativos na escolha de parceiros.

A segunda parte do estudo focou a questão do julgamento que as pessoas fazem das outras baseadas em preferências por gêneros e gosto musical. De um total de 214 respostas emergiram 147 adjetivos e expressões idiomáticas para os 7 gêneros. Estas foram listadas e distribuídas em 10 categorias emergentes: capacidades individuais, personalidade, julgamento de valor, educação, grupo social, atitudes, condição socioeconômica, localização geográfica e ideologia política. Palavras e expressões semanticamente similares, tais como "sofisticado" e "refinado", foram 
aglutinadas em um termo único. Dois experts em língua portuguesa e cultura brasileira examinaram a distribuição de adjetivos nas referidas categorias e a aglutinação de palavras e expressões idiomáticas em termos únicos. A confiabilidade dos experts foi calculada através da divisão do número de concordâncias por concordâncias mais discordâncias, e gerou os resultados de .94 para a distribuição dos adjetivos nas categorias e .89 para a aglutinação de palavras em um termo único. A figura 1 denota o percentual de respostas por categoria, antes da aglutinação de palavras em um termo único.

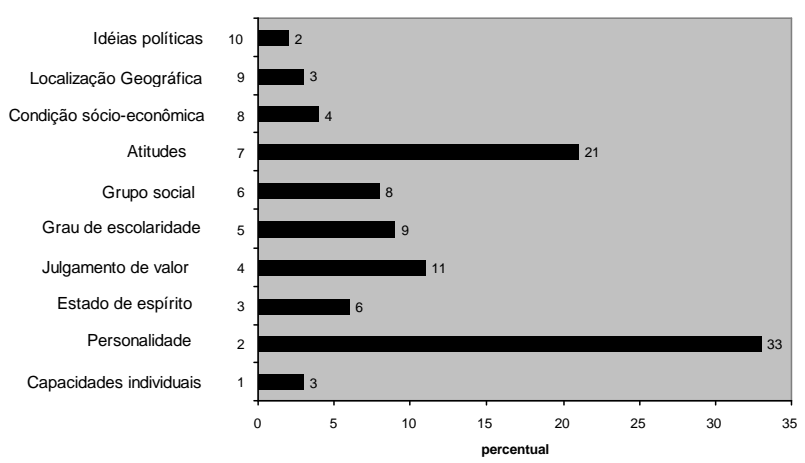

Figura 1. Distribuição de adjetivos em categorias emergentes

Embora alguns adjetivos pudessem ser colocados em mais de uma categoria, como ficou dito, os experts concordaram com a distribuição de cada um deles em apenas uma das dez categorias propostas, que foram criadas com o intuito de verificar se havia tendências nas respostas dos participantes. Ou seja, era de interesse desta investigação determinar se as associações entre estilos musicais e adjetivos/expressões idiomáticas estavam mais relacionadas a determinados grupos sociais, ou se o gosto musical está mais relacionado à personalidade. De uma forma geral, como sugere a figura 1, os participantes deste estudo tenderam a associar o gosto musical mais à personalidade e às atitudes do que a outras características. Contudo, uma análise aprofundada dos adjetivos e expressões idiomáticas em suas respectivas categorias revelou informações mais detalhadas sobre as tais associações. A tabela 1 ilustra as associações encontradas através da análise dos dados obtidos neste estudo. É importante salientar que somente os três adjetivos ou expressões mais citados aparecem na tabela 1 , em ordem decrescente. A única exceção se refere ao gênero musical "música do mundo", que obteve uma quantidade extremamente variada de respostas e produziu somente dois adjetivos e/ou expressões idiomáticas comuns.

Tabela 1. Características Pessoais dos Ouvintes por Gênero Musical

\begin{tabular}{|c|c|}
\hline Gênero Musical & Características dos ouvintes \\
\hline MPB & $\begin{array}{l}\text { saudosista } \\
\text { politizado(a) } \\
\text { inteligente }\end{array}$ \\
\hline Rock/Pop & $\begin{array}{l}\text { jovem (em idade ou espírito) } \\
\text { energético(a) } \\
\text { comum }\end{array}$ \\
\hline Música clássica & $\begin{array}{l}\text { culto (a) } \\
\text { calmo(a) } \\
\text { velho(a) }\end{array}$ \\
\hline Jazz & $\begin{array}{l}\text { culto(a) } \\
\text { sofisticado(a) } \\
\text { esnobe }\end{array}$ \\
\hline Sertanejo & $\begin{array}{l}\text { simples } \\
\text { interiorano(a) } \\
\text { sentimental }\end{array}$ \\
\hline Música do mundo & $\begin{array}{l}\text { eclético(a) } \\
\text { mente-aberta }\end{array}$ \\
\hline Samba/Pagode & $\begin{array}{l}\text { extrovertido(a) } \\
\text { energético(a) } \\
\text { de baixa renda }\end{array}$ \\
\hline
\end{tabular}

Replicando parcialmente os resultados de Zillman e Bhatia (1989), estereótipos de personalidade foram encontrados para alguns, mas não para todos os gêneros musicais. Outras associações estereotípicas estiveram relacionadas à estratificação social e status. Como exemplo, os resultados deste estudo sugerem que os participantes deste estudo associaram o jazz e a música clássica a pessoas cultas e instruídas, o que pode estar ligado à falta de democratização de sua oferta pela mídia e pelos órgãos culturais (veja Shepherd, 2001). Além disso, a música clássica foi fortemente associada aos velhos, o que pode estar relacionado à elitização da maneira de ouvir (o ouvinte precisa se deslocar ao teatro e deve se portar de maneira contida) e às freqüentes representações negativas e caricaturais da música clássica na mídia brasileira. Diferentemente, o pagode e o samba - este último há décadas considerado o gênero musical brasileiro por excelência (ver Sandroni, 2001) - são estilos acessíveis a todos, especialmente porque representam uma quantidade expressiva de membros de todas as classes da população brasileira. Além disso, o samba e o pagode estão associados ao carnaval, que é considerado a maior festa brasileira e é comemorado em todos os estados da nação. Talvez seja por esta razão que os participantes concordaram que os amantes do samba são pessoas extrovertidas e energéticas. 
Ironicamente, a MPB que se diz popular pareceu estar mais associada aos indivíduos educados e politizados que com a população em geral. Os ouvintes da MPB também foram percebidos como indivíduos altamente nostálgicos e saudosistas. A explicação para tal percepção pode estar ligada às próprias letras de muitas canções da MPB, que falam sobre a saudade de pessoas, eventos, lugares e de um país que não existe mais, ou ainda remontar aos tempos áureos desse estilo musical. Contudo, a maior convergência de adjetivos e expressões idiomáticas se deu quando a questão fez referência ao gênero sertanejo. Foi este o gênero que obteve o maior número de respostas similares, e foi, portanto, o maior consenso entre os participantes. Segundo estes últimos, os fãs de música sertaneja são pessoas humildes que vivem no campo ou que imigraram recentemente para a cidade grande, e que estão em contato direto com as próprias emoções, sendo muito sentimentais. Diferentemente, o rock e a música pop foram associados aos jovens, tanto por faixa etária quanto por "espírito". Já os ouvintes de música do mundo foram definidos como ecléticos e portadores de uma mente aberta. Como já foi dito anteriormente, este foi o gênero musical que gerou a maior quantidade de respostas opostas, tais como "introvertido e extrovertido" e "sonhador e realista". A ausência de estereótipos fortes neste caso pode estar relacionada ao fato de que a escuta do gênero música do mundo ainda é relativamente recente no país. É importante salientar que aproximadamente 1/3 dos participantes mencionou, por escrito, ser esta a parte mais complexa do estudo. Curiosamente, a maioria citou mais que três adjetivos e/ou expressões idiomáticas para um determinado gênero e um (ou nenhum) para outro. Contudo, devido às especifidades e tamanho da amostra estudada, é necessário muita cautela ao fazer generalizações acerca dos estereótipos associados à música encontrados pelo presente estudo. É possível que exista uma relação direta entre o conhecimento musical e o gosto do participante e sua percepção dos ouvintes de música. Pesquisas futuras podem investigar esta questão e verificar se há variações regionais e econômicas dos estereótipos associados à música em outras amostras.

A última parte do estudo consistiu em três questões abertas e duas questões dicotômicas (do tipo sim/não). As primeiras duas perguntas foram: - "Você acha que a música exerce algum papel na sua vida amorosa? Por quê?" Apenas 14\% da amostra afirmaram que a música não tinha nenhuma importância em sua vida amorosa. Os demais $86 \%$ argumentaram que a música é importante na vida amorosa, porque ajuda a criar uma certa atmosfera que influencia o humor e os sentimentos $(80 \%)$, dá sensibilidade aos indivíduos e aos casais $(71 \%)$, ajuda a desenvolver a integração $(668 \%)$ e levar ao romance $(67 \%)$. A música também foi mencionada como um elemento de indução da memória $(54 \%)$.

As questões seguintes envolviam a atração interpessoal: "Você namoraria alguém que tem um gosto musical diferente do seu? Por quê?" Mais uma vez, apenas 14\% da amostra disseram que jamais namorariam alguém que tivesse um gosto musical diferente do seu. Um detalhe interessante foi que este subgrupo continha o dos participantes de maior idade de toda a amostra. De acordo com estes participantes, gostos musicais contrastantes causam problemas nos relacionamentos amorosos, uma vez que influenciam e até mesmo dificultam as atividades de lazer dos casais. Três participantes também sugeriram que diferenças no gosto musical refletem diferenças sociais e educacionais, elementos essenciais para um relacionamento sadio. Ainda assim a maioria dos participantes demonstrou certa abertura para namorar pessoas com gostos musicais contrastantes, e, também para aprender novos estilos musicais com o(a) parceiro(a). Tudo indica que há questões mais importantes num relacionamento a dois do que o gosto musical, incluindo a convivência diária e o respeito às diferenças. Quarenta por cento dos participantes mencionaram a importância de respeitar o gosto dos parceiros e de se beneficiarem das diferenças.

A última questão do estudo solicitou dos participantes uma descrição de pelo menos um episódio em que a música teve um papel importante em suas vidas. Apenas $8 \%$ da amostra disseram não se lembrar de nenhum momento importante. Todos os demais mencionaram um ou mais episódios nos quais a música realçou os acontecimentos de suas vidas. Grande parte dos episódios $(92 \%)$ citados esteve relacionada às diferentes formas de relações interpessoais. A maioria dos participantes $(78 \%)$ descreveu a importância da música na vida social através de comemorações em família, festas, passeios com amigos e amantes, viagens e cerimônias religiosas tais como casamentos e batizados. A música também foi citada como fonte vital de energia na adolescência, ajudando a combater a solidão e a raiva e a memorizar fórmulas e conceitos das disciplinas escolares (39\%). Para outros participantes, a música serviu como fonte de distração em viagens longas, no trabalho e no trânsito (36\%). A música ainda foi citada como fonte de apoio para as horas difíceis de tristeza, desespero e luto, assim como para combater o estresse (35\%). Vale notar que vários participantes (23\%) forneceram exemplos de peças musicais específicas usadas para obterem níveis diferentes de excitação: música lenta para acalmar, música rápida e em volume 
elevado para "levantar o astral" ou animar. Finalmente, a música foi citada por $11 \%$ dos participantes como a forma mais acessível de arte, capaz de libertar a mente das preocupações cotidianas, como a violência urbana e a falta de recursos financeiros.

Uma análise aprofundada dos dados desta terceira parte do estudo revelou quatro usos distintos da música no contexto das relações interpessoais. Estes usos da música apareceram em pelo menos $67 \%$ das respostas. São eles:

- Objetivos de excitação - A música tem a função de aumentar ou diminuir o estado de excitação dos ouvintes, como foi sugerido por North \& Hargreaves (1997). Os indivíduos podem escolher gêneros musicais diferentes dependendo do contexto social em que se inserem. Ritmo e andamento musicais parecem ter uma função importante. Em geral, música rápida serve para aumentar o estado de excitação do indivíduo, enquanto música lenta tem uma função de relaxamento.

- Fundo acústico - A música é um elemento importante na criação de atmosferas ou ambientes sonoros, inclusive no preenchimento de "lacunas" deixadas pela ausência de conversação ou interação entre as pessoas no decorrer de um evento social (veja Huron, 1999).

- Facilitadora de atividades que promovem a aproximação de indivíduos - A música constitui a base da dança, que é um elemento facilitador de encontros interpessoais (Crozier, 1997). Outras atividades - como cantar em um coral, participar de um conjunto instrumental ou assistir a um concerto ou show - constituem atividades musicais que promovem a aproximação dos indivíduos.

- Artefato mnemônico - A música facilita o armazenamento de eventos significativos na memória (Levitin, 2000). É comum casais e amigos elegerem uma canção musical como um ícone de representação de seu relacionamento. Sendo assim, cada vez que a referida peça ou canção musical é tocada, memórias do relacionamento podem reaparecer.

\section{CONCLUSÃO}

De maneira geral, os resultados deste estudo reforçam a idéia de que a música exerce um papel importante nas relações interpessoais. Muito embora a música não tenha aparentado exercer um efeito direto sobre a atração interpessoal e a escolha de parceiros, ela pareceu ter um efeito indireto e generalizado sobre as relações interpessoais. Corroborando estudos anteriores (Zilmann \& Bhatia, 1989), este estudo encontrou alguns estereótipos de personalidade diretamente relacionados a alguns gêneros musicais, bem como esterótipos relacionados à estratificação social e ao status. Esses estereótipos influenciam a atração interpessoal, ainda que de forma inconsciente, porque a atração está diretamente relacionada às respostas pessoais aos estereótipos associados aos gêneros musicais (Zilmann \& Bhatia, 1989). Ou seja, tomando-se o ponto de vista da psicologia cognitiva, este estudo corrobora a idéia de que a música está relacionada à atração, que por sua vez, está diretamente ligada aos esquemas cognitivos, que são fruto de experiências e relacionamentos anteriores com colegas, pais e responsáveis.

Ainda no campo da psicologia cognitiva, a música parece constituir um artefato mnemônico que estabelece ligações entre as pessoas e os eventos, ajudando a armazená-los na memória. Já quanto à evolução, a música parece dar sua contribuição através da facilitação de atividades que promovem a aproximação de indivíduos e da criação de cenários (i.e., ou os chamados "climas propícios") para o desabrochar das relações interpessoais de natureza amorosa, que constituem a base da continuação da espécie. Portanto, a proposição de que a música não tem lugar na evolução, citada no início deste artigo, precisa ser urgentemente revista.

A sugestão de Pinker (1997) de que nossas vidas permaneceriam praticamente inalteradas na ausência da música está longe de ser convincente, primeiramente, devido ao seu caráter. Se todas as sociedades do mundo têm mantido formas de fazer música e atribuem sentidos próprios a estas, deve haver alguma razão para tal fenômeno. Não é difícil percebermos que a música está por todas as partes, e faz parte da vida de diversos povos, religiões e formas de lazer. Das mães que cantam para os seus bebês aos adolescentes que ensaiam uma banda de rock na garagem; da debutante que valsa com seu pai aos noivos que trocam alianças na igreja ao som de "Ave Maria"; dos filhos de imigrantes japoneses que cantam num karaokê aos carnavalescos que dançam incessantemente celebrando, apesar dos pesares, a alegria de viver: todos estes e demais usos da música integram e dão algum sentido à vida cotidiana.

Além disso, a idéia de Pinker (1997) não convence porque não há uma única definição do que é a música, mas muitas definições possíveis, que ultrapassam as fronteiras do Mundo Ocidental, bem como as bordas entre o que a maioria das pessoas define como música e como linguagem, sobretudo no 
início da vida (consulte Borges Neto, 2005; Fernald, 1989; Ilari, 2002; 2003); sem falar que, como foi visto anteriormente, a música parece aproximar os indivíduos, além de promover a interação social e de trazer riqueza cultural e diversidade. Portanto, por que deveríamos viver sem ela?

\section{REFERÊNCIAS}

Abeles, H. F., Hoffer, C. R. \& Klotman, R. H. (1995). Foundations of music education. New York: Schirmer Books.

Borges Neto, J. (2005). Música é linguagem? Em M. Dottori, B. Ilari \& R. C. Souza (Orgs.). Anais do Primeiro Simpósio de Cognição e Artes Musicais. Curitiba: Editora do DeArtes, . 19.

Campbell, P. (1996). Music in cultural context: Eight views on world music education. Reston: MENC.

Cross, I. (1999). Is music the most important thing we ever did? Music, development and evolution. In Y. I. Suk Won (Ed.). Music, mind \& science (pp. 29-47.) Seoul: Seoul National University Press.

Crozier, W. R. (1997). Music and social influence. In D. J. Hargreaves \& A. C. North (Eds.). The social psychology of music, (pp. 67-83). Oxford: Oxford University Press.

Felmlee, D. \& Sprecher, S. (2000). Close relationships and social psychology: Intersection and future paths. Social Psychology Quarterly, 63, 365-376.

Fernald, A. (1989). Intonation and communicative intent in mothers' speech to infants: Is the melody the message? Child Development, 60, 1497-1510.

Feingold, A. (1990). Gender differences in effects of physical attractiveness on romantic attraction: A comparison across five research paradigms. Journal of Personality and Social Psychology, 59, 981-993.

Fletcher, G. J. O., Giles, L. Simpson, J. A. \& Thomas, G. (1999). Ideals in intimate relationships. Journal of Personality and Social Psychology, 76, 72-89.

Gregory, A. H. (1997). The roles of music in society: the ethnomusicological perspective. In D. J. Hargreaves \& A. C. North (Eds.). The social psychology of music. (pp. 123-140). Oxford: Oxford University Press.

Huron, D. (1999). Lecture 2: An instinct for music: Is music an evolutionary adaptation? In The 1999 Ernest Bloch Lectures. Disponível em <www.musiccog.ohiostate.edu/Music220/Bloch.lectures/2.Origins.html> (Acesso em: 09/02/06).

Ilari, B. (2001). Capoeira and music education: Ideas, suggestions and possibilities. Canadian Music Educator, 43, 19-24.

Ilari, B. S. (2002). Music perception and cognition in the first year of life. Early Child Development and Care, 172, 311-322.

Ilari, B. S. (2003). Research on music, the brain and cognitive development: Addressing some common questions of music educators. Music Education International, 2, 85-93.
Ilari, B. S. \& Majlis, P.(2002). Children's songs from around the world: An interview with Francis Corpataux. Music Education International, 1, 1-14.

Johnson, J. D., Trawalter, S. \& Dovidio, J. F. (2000). Converging interracial consequences of exposure to violent rap music on stereotypical attributions of blacks. Journal of Experimental Social Psychology, 36, 233-251.

Juslin, P. N. \& Sloboda, J. A. (2001). Music and Emotion: Theory and Research. Oxford: Oxford University Press.

Krumhansl, C. L. (1997). An exploratory study of musical emotions and psychophysiology. Canadian Journal of Experimental Psychology, 51, 336-352.

Levitin, D. (2000). In search of the musical mind. Cerebrum: The Dana Forum on Brain Science, 2(4), 31-49.

Myers, D. G. (1993). Social Psychology. New York: McGraw Hill.

North, A. C. \& Hargreaves, D. J. (1997). Experimental aesthetics and everyday music listening. In D. J. Hargreaves\& A. C. North (Eds). The Social Psychology of Music, (pp. 84-103).Oxford: Oxford University Press.

Pinker, S. (1997). How the mind works. New York: W.W. Norton Company.

Priel, B. \& Besser, A. (2000). Adult attachment styles, early relationships, antenatal attachment, and perceptions of infant temperament: A study of first-time mothers. Personal Relationships, 7, 291-310.

Reeder, H. M. (2000). "I like you....as a friend": The role of attraction in cross-sex friendship. Journal of Social Psychology and Personal Relationships, 17, 329-348.

Sandroni, C. (2001). Feitiço Decente. Rio de Janeiro: Jorge Zahar.

Shepherd, J. (2001). Music and social categories. In M. Clayton, T. Herbert \& R. Middleton (Eds.). The cultural study of music (pp. 69-80). New York: Routledge.

Sloboda, J. A. (1991). Music structure and emotional response: Some empirical findings. Psychology of Music, 19, 110120.

Trehub, S. E. \& Schellenberg, E. G. (1995). Music: Its relevance to infants. Annals of Child Development, 11, 124.

Wapnick, J., Mazza, J. K. \& Darrow, A. A. (1998). Effects of performer attractiveness, stage behavior, and dress on violin performance evaluation. Journal of Research in Music Education, 46, 51-521.

Zillman, D. \& Bhatia, A. (1989). Effects of associating with musical genres on heterosexual attraction. Communication Research, 16, 263-288.

Recebido em 27/04/2005 Aceito em 31/01/2006

Endereço para correspondência: Beatriz Ilari. Rua Coronel Dulcídio, 638, Bairro Batel, CEP 80420-170,Curitiba-PR. E-mail:beatrizilari@yahoo.ca 